\title{
U ma nova opção para contenção no tratamento do linfedema em crianças
}

\section{A new option for compression in the treatment of lymphedema in children}

\author{
M aria Elisa Simões Artíbale', José M aria Pereira de G odoy², \\ M aria de Fátima G uerreiro Godoy ${ }^{3}$, D omingo M arcolino Braile ${ }^{4}$
}

\begin{abstract}
Resumo
U $m$ das principais dificuldades encontradas no tratamento do linfedema em crianças são os mecanismos de contenção. 0 objetivo do presente estudo é rel atar uma experiência inicial com meias de gorgurão em criança. D escrevem-se as dificuldades encontradas no tratamento do linfedema em uma criança e mostra-se uma alternativa de contenção, que é a meia de gorgurão.
\end{abstract}

Palavras-chave: linfedema, criança, tratamento.

\begin{abstract}
O ne of the main difficulties found in thetreatment of lymphedema in children is the mechanism of compression that should be used. The objective of present study was to report an initial experience with infant gorgurão (cotton-polyester textile) stockings. The difficulties found in the treatment of infant lymphedema are described and an alternative method of compression using a gorgurão stocking is provided.
\end{abstract}

Key words: lymphedema, child, treatment.

ve a drenagem linfática, bandagens e terapia medicamentosa para evitar infecções, orientação de atividades de vida diária dessas crianças para as mães, apoio psicológico para a criança e familiares ${ }^{3-8}$.

U ma das grandes dificuldades en contrada no tratamento do linfedema são as meias e bandagens. 0 objetivo do presenteestudo é relatar uma experiência inicial com meias de gorgurão em crianças.

\section{Relato de caso}

Relata-se o caso de uma criança quefoi encaminhada, aos 18 meses de idade, ao vascular, com história de edema nos membros inferiores desde o nascimento. A mãe informa que ela foi encaminhada logo após 0 nascimento para um centro de atendimento de saúde, com suspeita de problemas renais. Contudo, os exames complementares não constataram alterações. N o exame físico, foi feito diagnóstico clínico de linfedema congê nito nos dois membros (Figura 1). I niciou-se tratamento, que incluiu a drenagem linfática manual, adaptada a crianças (estímulo cervical, compressão de abdome e estímulo na região inguinal), orientação dos cuidados higiênicose prevenção das infecções. D evido à distância entre 0 centro de atendimento e sua residência, foi 
proposto o treinamento intensivo da mãe para realizar a terapia diariamente em sua casa. Esse treinamento durou 15 dias e, posteriormente, foi solicitada uma nova avaliação a cada 30 dias. A mãe foi treinada para realizar o tratamento em casa, porém a criança não mostrou melhora no retorno, e a mãe relatou não ter paciência para tal tratamento. D evido às dificuldades relacionadas aos cuidados, optou-se pela adaptação, confecção e uso contínuo da meia de gorgurão. Esse tecido é feito de poliéster e al godão e, por ser canelado, apresentauma extensibilidadediferente, deacordo com o sentido dasfibras. I sso permitequeel efuncione como um material de baixa extensibilidade, no sentido contrário dasfibras, edemédia elasticidade, no sentido das fibras.Portanto estas características e a sua resistência permitequeseja adaptado parafunção. A meiaéconfeccionada com vel cro, o quepossibilita um melhor ajuste, à medida que o membro vai reduzindo a sua circunferência. Esse material pode ser encontrado em lojas de tecidos, porém a fabricação pode apresentar pequenas variações, de acordo com o fabricante. D urante 2 anos seguidos, essa criança foi acompanhada, mensalmente, pela equipe de atendimento, médico linfologista, fisioterapia, terapia ocupacional, psicologia, com reduções dediâmetro do membro, porém com grandes dificuldades em relação aos cuidados necessários, sendo sempre necessária a intervenção do serviço de assistência social para verificação da continuidade do tratamento em casa e de outras necessidades detectadas para o melhor desenvolvimento psicomotor e social dessa criança. Entretanto, nos meses em que a criança fez uso das meias, apresentou redução clínica e perimétrica do membro (Figuras 2 e 3).

\section{D iscussão}

U ma das grandes dificuldades no tratamento do linfedema em crianças no Brasil são os mecanismos de contenção, tanto em relação às bandagens quanto às meias. U ma das alternativas encontradas por G odoy \& Godoy foi a criação de uma meia confeccionada com tecido de gorgurão para os adultos, a qual foi adaptada para crianças. No presente estudo, essa adaptação foi satisfatória quanto à funcional idade. N o entanto, ocorreram dificuldades quanto à conscientização sobre a evolução da doença eadesão da família e do pacienteao tratamento. 0 hábito de andar descalço foi 0 grande empecilho na adesão. A alternativa de sugerir que a criança passasse a freqüentar uma escola, onde a assistente social local, coordenadora e professores foram

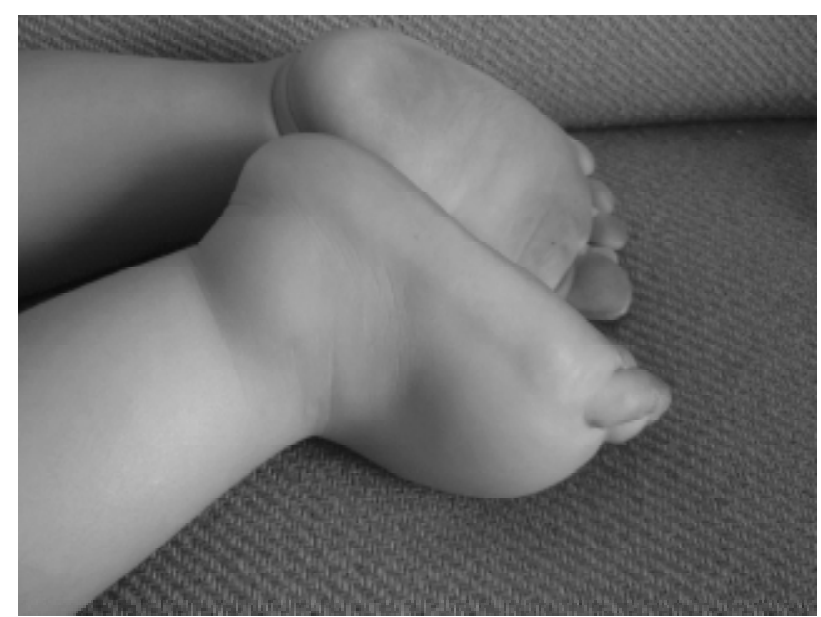

Figura 1 - Linfedema característico no pé da criança na avaliação inicial

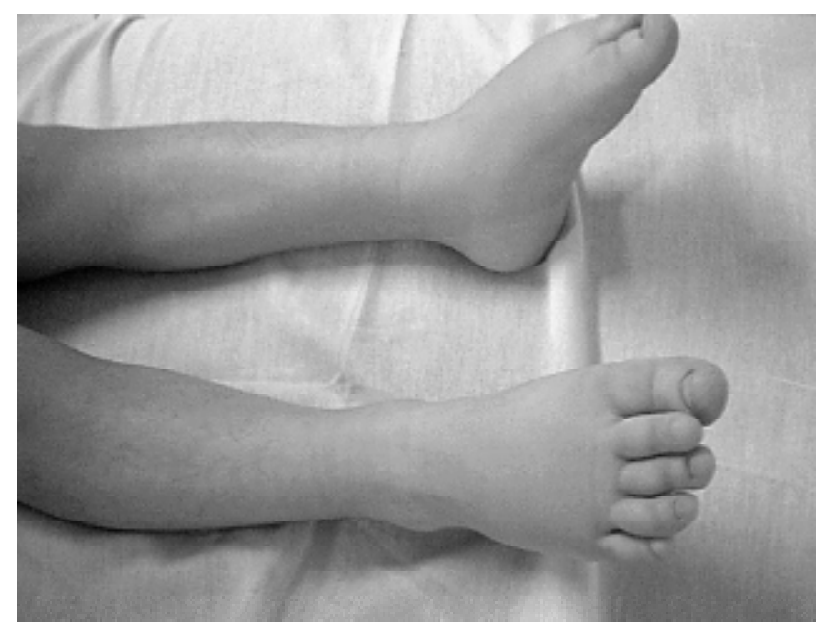

Figura 2 - Redução do edema após 2 anos deacompanhamento

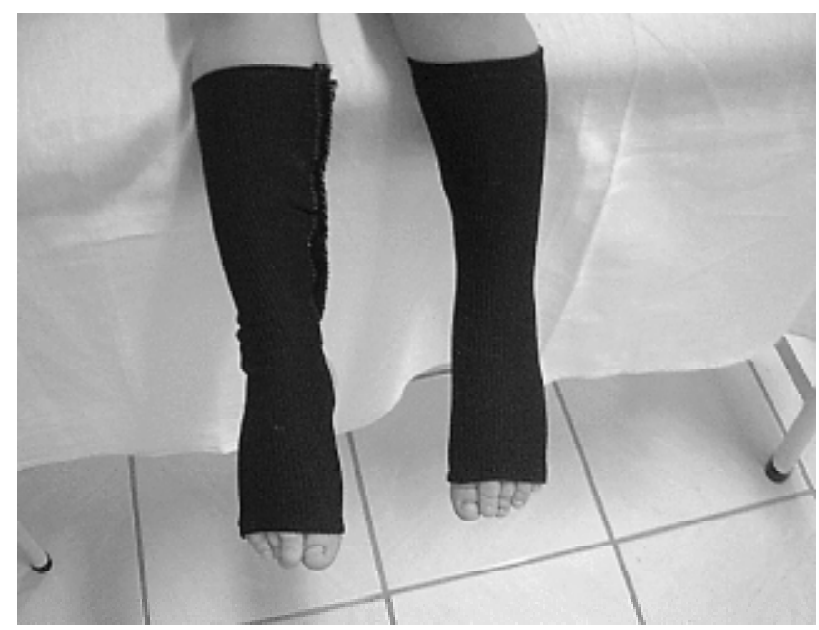

Figura 3 - Criança fazendo uso da meia de meia degorgurão 
orientados pela equipe sobre a doença, sua evolução ea necessidade do tratamento, a importância do uso da meia diariamente para manter as reduções conseguidas e evitar o aumento de volume do membro foi uma alternativa viável para o uso da meia, cuidados diários, estimular o desenvolvimento psicomotor e a socialização dessa criança.

U ma grande vantagem do gorgurão éo custo, além da facilidade na colocação e remoção da meia, dando maior liberdade ao paciente em todas as atividades.

Essa nova abordagem, proposta no tratamento de crianças portadoras de linfedema, desperta para uma nova realidade frente ao tratamento dessa doença. 0 uso da meiaéum recurso para o tratamento em crianças com asquaisnão há possibilidade detratamento ambulatorial efetivo, às vezes pela distância dos centros de tratamento ou pela condição socioeconômica, que não permiteavinda desse pacienteao tratamento. Entretanto, necessita de apoio dos familiares, ou então precisa buscar alternativas na comunidade do paciente pelos profissionais que o assistem, a fim de manter essa abordagem terapêutica.

\section{C onclusão}

A adaptação e uso da meia de gorgurão no tratamento do linfedema em crianças permitem reduzir o edema, amenizando a progressão do linfedema. 0 envolvimento efetivo da família e/ ou da comunidadeé fundamental para bons resultados.

\section{R eferências}

1. GodoyJM. Fisiopatologiado sistemalinfático. In: GodoyJM, Belczak CE, Godoy M F. Reabilitação linfovenosa. Rio de Janeiro: DiLivros; 2005. p. 37-41.

2. Godoy JM, Godoy M F. D renagem linfática manual. U ma nova abordagem. São J osé do Rio Preto: Lin Comunicação; 1999.

3. Allen EV. Lymphedema of the extremities. Classification, etiology and differential diagnosis. A study of 300 cases. Arch Intern M ed. 1934;54:602-29.

4. Godoy JM, Godoy M F. D renagem linfática manual: novo conceito. J Vasc Br. 2004;3:77-80.

5. GodoyJ M, Godoy M F. D renagem linfáticano tratamento de linfedema em adolescentes. Rev Angiol Cir V asc. 2004;1:6-7.

6. Godoy JM, Godoy M F.Avaliação de meia de tecido não elástico no tratamento de linfedema de membros superiores. Lymphology. 2002/3;35(Suppl 2):S256-63.

7. Godoy MF. Atividades de vida diária no tratamento do linfedema. Lymphology. 2002/03;35(Suppl 2):S213-5.

8. Ciucci JL, Krapp JC, Soracco JE, et al. Clínica e evolução na abordagem terapêutica interdisciplinar em 640 pacientescom linfedema durante 20 anos. J V asc Br.2004;3:72-6.

Correspondência:

J osé M aria Pereira de G odoy

Rua Floriano Peixoto, 2950

CEP 15010-020 - São J osé do Rio Preto, SP

E-mail: godoyjmp@riopreto.com.br 